\title{
Post-Traumatic Epilepsy: Incidence and Mechanisms after Brain Injury
}

\author{
Timothy Van Meter ${ }^{1 *}$ and Anil Kumar ${ }^{2}$ \\ ${ }^{1}$ Program for Neurological Diseases, ImmunArray Inc., USA \\ ${ }^{2}$ Department of Neurology, Great Plains Health, USA
}

Submission: April 21, 2018; Published: June 25, 2018

*Corresponding author: Timothy Van Meter, ImmunArray, 737 N 5th Street, Suite 304 Richmond, VA 23219, USA, Fax: 804-709-0152; Tel: 804709-0151; Email: tim.vanmeter@immunarray.com

\begin{abstract}
Post-traumatic epilepsy can result from traumatic brain injury (TBI) due to a number immediate and chronic changes to the cellular environment in the affected tissues. This form of acquired epilepsy represents $20 \%$ of symptomatic epilepsy cases and relates to injury severity. The pathological mechanisms occurring after TBI that give rise to seizure initiation include an early phase (early PTE 1-7 days post-injury) and a late phase which can occur months to years after TBI. The pathological mechanisms at early and late onset PTE differ, and are still poorly understood. Underlying mechanisms are reviewed in the context of epileptogenesis, and prophylactic use of medications is briefly reviewed for both pediatric and adult patients in relation to outcomes. PTE is a concerning adverse health outcome as a consequence of TBI, and should be assessed and monitored with newer advances in bedside point of care technologies. Technologies such as blood biomarker tests and portable EEG devices hold promise for diagnosing and even predicting PTE.
\end{abstract}

Keywords: Traumatic Brain Injury (TBI); Seizure; Post-traumatic epilepsy(PTE)

\section{Overview/Disease Burden}

Post traumatic epilepsy (PTE) is a form of epilepsy that results from brain damage caused by physical trauma to the brain (traumatic brain injury) and is defined as occurrence of more than one seizure related to the injury itself, occurring after one week of traumatic brain injury [1]. PTE is the most common cause of acquired epilepsy, comprising around 20\% of symptomatic epilepsy cases and $5 \%$ of all cases of epilepsy. It is the most common cause of epilepsy with onset in young adulthood. Head injury increases the risk of developing epilepsy by three times as compared to general population [2-5]. The probability of post traumatic epilepsy is estimated to be $0.7 \%$ with mild TBI, $1.2 \%$ with moderate TBI, and $10 \%$ with severe traumatic brain injury over a five year period. The incidence is much higher with penetrating head injuries, as compared to blunt closed head trauma. The prevalence of post-traumatic epilepsy has also been found to have increased over the last 30 years, likely due to an increase in patient survival after severe brain injury $[6,7]$.

\section{Pathophysiology of PTE}

Seizures following TBI can be categorized in three groups based on the time of onset: Immediate, Early and Late onset seizures. Seizures occurring within 24 hours of injury are categorized as Immediate onset and are thought to be due to immediate repercussion impact of the injury that stimulates brain tissue with low seizure threshold $[1,6]$. They are more common in children. Early onset posttraumatic seizures occur within one week of traumatic insult. The mechanism of these seizures is thought to be related to the initial trauma and shearing forces, causing diffuse axonal injury and focal brain injury, caused by direct impact or brain movement inside the skull, or by penetrating wounds. Such mechanisms are followed by secondary axonal injury, due to swelling, retraction, and degeneration of injured neurons. Secondary effects from head trauma like cerebral edema, hemorrhage and contusion, causes alteration in blood brain barrier, damage of tissues due to release of free oxygen radicals and cytokines, the influx of calcium into open ion channels, and the release of excitatory neurotransmitters like glutamate [7-9]. Incidence depends on the severity of injury and $10-15 \%$ of adults and 30 to $35 \%$ of children develop early onset seizures after severe TBI. Early PTS is the most significant risk factor for development of PTE in adults $[6,10]$. Nonconvulsive seizures (detected by continuous EEG) are more common than convulsive seizure in first week 
following TBI, although their clinical significance is debatable [9].

Late onset seizures occur after one week of traumatic brain injury. Risk of PTE is highest within the first two years. About $50 \%$ of PTE cases, seizures begin in first year and within two years in about $80 \%$. High number of seizures in first year of onset is positively correlated with seizure severity and intractability. 15 to $20 \%$ patients may have their first seizure after two years of brain injury $[10,11]$. The pathophysiology of late seizures is complex, an a subject of ongoing research. Late onset seizures following TBI involve a latent period of epileptogenesis during which there is transformation of normal brain into brain with epileptic foci causing recurrent, unprovoked seizures [7]. Most of the research and current understanding of molecular mechanisms of epileptogenesis in PTE is based on experimental animal models. Exploring these mechanisms further and identifying biomarkers involved in epileptogenesis is an interesting ongoing research subject that could potentially target therapies for PTE prevention.

Early damage following TBI is due to interruption in blood flow and oxygenation, which activates an ischemic cascade. This, in turn, favours anaerobic metabolic pathways, and leads to failure of ATP-dependent ion channels and proteins. With impaired ion transport across cell membranes in neurons and glia, cell function and viability is affected. This can lead to cell death by deregulation of excitatory neurotransmitters, primarily glutamate. Calcium ion $\left(\mathrm{Ca}^{2+}\right)$ influx leads to glutamate release, and decreased glial uptake by specific glutamate transporters further elevates glutamate levels. Excess glutamate binds to NMDA receptors and promotes $\mathrm{Ca}^{2+}$ and sodium $\left(\mathrm{Na}^{+}\right)$influx, which further activates enzymes responsible for cell damage. Upregulation of $\mathrm{Ca}^{2+}$ also increases Nitric oxide(NO) synthesis, causing further oxidative damage [12]. Recent research has suggested NO metabolites could be used as biomarkers for severe TBI [13]. Intracellular accumulation of $\mathrm{Ca}^{2+}$ promotes mitochondrial sequestration of $\mathrm{Ca}^{2+}$ stores, the elevation of which can impair oxidative phosphorylation and cause production of reactive oxygen species (ROS). ROS production can then lead to further brain cell damage, and underlies seizure formation [12]. Parenchymal blood after TBI is also associated with an increase in risk of PTE. Heme and iron have both been shown to have effects on synaptic transmission that may cause epileptogenesis [6].

\section{Results from of Animal Models of PTE}

Several animal models have been used to investigate epileptogenesis following TBI, including Fluid percussion injury (FPI) models, controlled cortical impact (CCI) models, weight drop injury models, neocortical undercut models, and blast injury models [7]. Several studies have identified potential causes of seizures following TBI. However, the predominant cause is debatable. Studies have identified signs like mossy fiber sprouting, damage to hippocampus, blood brain barrier disruption as potential precursors of PTE [1]. Two types of cell loss are associated with epileptogenesis following TBIhippocampal sclerosis and loss of interhilar neurons [1]. Late seizures are thought to be caused by cortical damage due to iron deposition and elevated levels of excitatory amino acid Glutamate. Postinjury self recovery process causes reorganization of brain circuitry and the newly created connections causes hyperexcitability between the new synapses particularly in dentate gyrus, which further increases hippocampal excitability. Blood brain barrier disruption and inflammation following TBI leads to further damage and seems to have an effect on PTE. Greater and prolonged BBB disruption is seen in patients with PTE $[1,12]$.

Hippocampus and cortex are known to be more prone to epileptic activity. In rat hippocampus, TBI reduced A-type $\mathrm{K}+\mathrm{channel}$ expression and ion flow, causing neuronal hyperexcitability. Hippocampal mossy fibers connecting granule cells of dentate gyrus with Cornu Ammonis sub-region 3 (CA3) are reorganized, possibly due to activation of trkB-ERK1/2CREB/El-1 signalling pathways. Such changes favor the extension of neuronal processes and mossy fiber sprouting (MFS) and alters neural circuitry $[12,14]$. MFS by itself does not cause seizures, but is believed to be necessary for epileptiform activity. Mossy fiber sprouting is believed to be dependent on severity of TBI. MFS and hilar neuronal loss in the dentate gyrus has been seen in the molecular and histological analysis of hippocampi of PTE patients [12,15]. Another mechanism thought to promote seizures after TBI is the reduction of inhibitory GABA currents. Reduction in GABAA currents in ipsilateral DG granule cells at one month post-TBI, and eventually contralateral hippocampus at six months following injury, have been demonstrated in FPI rat models $[12,16]$.

Overall, alterations in hippocampal inhibitory and excitatory circuits promote seizures after TBI. Volumetric MRI in PTE patients has also demonstrated greater hippocampal atrophy. Hippocampus neuroimaging changes remain a potential area for biomarkers that could identify susceptibility to PTE $[12,17]$. Cortex is also prone to epileptic activity, as demonstrated by studies on CCI rat models that showed abnormal and spontaneous discharges in pyramidal cell layer $\mathrm{V}$ of neocortex following one week and two week of injury respectively [18].

\section{Treatment and monitoring for PTE}

Only 25 to $40 \%$ of patients with PTE achieve remission with medications, and there is a high recurrence rate when medications are discontinued [7]. More research is needed to find newer and more effective pharmacological targets, and administering antiepileptics with the appropriate timing may help in preventing the onset of PTE. In addition to pharmacological research, novel portable EEG monitoring devices have been in development in the past decade that can be used in the hands of athletic trainers, military field medics, primary care clinics, emergency medicine, and other clinical settings that can reveal PTE abnormalities in 


\section{Open Access Journal of Neurology \& Neurosurgery}

a short time frame (20-30 minutes), which may be useful for initial diagnosis of TBI with a PTE component, and for rapid, cost effective monitoring of PTE during follow-up valuations. These technologies and other monitoring tests such as blood based biomarkers, may allow for more sensitive and informative monitoring of TBI patients, and provide useful monitoring methods to guide the evaluation of new therapeutic interventions for PTE in the TBI population.

\section{References}

1. Mc Donnell E, Kolakowsky-Hayner SA (2014) Post traumatic epilepsy: A review of triggers and potential treatments after brain injury. Int J Neurorehabilitation 1: 115.

2. Annegers JF, Rocca WA, Hauser WA (1980) Causes of epilepsy: contributions of the Rochester epidemiology project. Neurology 30(9): 912-919.

3. Hauser WA, Annegers JF, Rocca WA (1996) Descriptive epidemiology of epilepsy: contributions of population-based studies from Rochester Minnesota. Mayo Clin Proc 71(6): 576-586

4. Gallagher D (2002) Post-traumatic epilepsy: An overview. Albert Einstein College of Medicine. Einstein Quart. J Biol Med 19: 5-9.

5. Jay R, Gavvala, Stephan U Schuele (2015) Post traumatic epilepsy. In: Elaine Wyllie (Ed.), Wyllie's treatment of epilepsy: Principles and practice. Chapter $28,\left(6^{\text {th }}\right.$ edn), Lippincott and Williams, New York, USA.

6. Annegers JF, Hauser WA, Coan SP, Rocca WA (1998) A populationbased study of seizures after traumatic brain injuries. N Engl J Med 338(1): 20-24.

7. Thurman D, Guerrero J (1999) Trends in hospitalization associated with traumatic brain injury. JAMA 282(10): 954-957.

8. Adams H, Mitchell DE, Graham DI, Doyle D (1977) Diffuse brain damage of immediate impact type: Its relationship to primary brain stem damage in head injury. Brain 100(3): 489-502.
9. Ding K, Gupta PK, Diaz-Arrastia R (2016) Epilepsy after traumatic brain injury. In: Laskowitz D, Grant G (Eds.), Translational Research in Traumatic Brain Injury. Chapter 14, Frontiers in Neuroscience, CRC Press/Taylor and Francis Group, Boca Raton, Florida, USA.

10. Verellen RM, Cavazos JE (2010) Post-traumatic epilepsy: an overview. Therapy 7(5): 527-531.

11. Lamar CD, Hurley RA, Rowland JA, Taber KH (2014) Post-traumatic epilepsy: review of risks, pathophysiology, and potential biomarkers. J Neuropsychiatry Clin Neurosci 26(2): iv-113.

12. Algattas H, Huang JH (2013) Traumatic brain injury pathophysiology and treatments: early, intermediate, and late phases post-injury. Int J Mol Sci 15(1): 309-341.

13. Kandasamy R, Kanti Pal H, Swamy M, Abdullah J (2013) Cerebrospinal fluid nitric oxide metabolite levels as a biomarker in severe traumatic brain injury. Int J Neurosci 123(6): 385-391.

14. Hu B, Liu C, Bramlett H, Sick TJ, Alonso OF, et al. (2004) Changes in trkB-ERK1/2-CREB/Elk-1 pathways in hippocampal mossy fiber organization after traumatic brain injury. J Cereb Blood Flow Metab 24(8): 934-943.

15. Swartz BE, Houser CR, Tomiyasu U, Walsh GO, DeSalles A, et al. (2006) Hippocampal cell loss in posttraumatic human epilepsy. Epilepsia 47(8): 1373-1382.

16. Pavlov I, Huusko N, Drexel M, Kirchmair E, Sperk G, et al. (2011) Progressive loss of phasic, but not tonic, GABAA receptor-mediated inhibition in dentate granule cells in a model of post-traumatic epilepsy in rats. Neuroscience 194: 208-219.

17. Vespa PM, McArthur DL, Xu Y, Eliseo M, Etchepare M, et al. (2010) Nonconvulsive seizures after traumatic brain injury are associated with hippocampal atrophy. Neurology 75(9): 792-798.

18. Yang L, Afroz S, Michelson HB, Goodman JH, Valsamis HA, et al. (2010) Spontaneous epileptiform activity in rat neocortex after controlled cortical impact injury. J Neurotrauma 27(8): 1541-1548.

\section{Your next submission with Juniper Publishers} will reach you the below assets

- Quality Editorial service

- Swift Peer Review

- Reprints availability

- E-prints Service

- Manuscript Podcast for convenient understanding

- Global attainment for your research

- Manuscript accessibility in different formats

( Pdf, E-pub, Full Text, Audio)

- Unceasing customer service

Track the below URL for one-step submission

https://juniperpublishers.com/online-submission.php 